\section{Training for Sport and Activity} Jack H. Wilmore and David L. Costill Leeds: Human Kinetics Publishers (Europe), ISBN 087322557 0, 1993, $436 \mathrm{pp}, £ 19.50$

For those who teach exercise physiology to undergraduate students, there has long been a need for a textbook that offers an alternative to the standard Astrand and Rodahl. This is probably that book. It is a wideranging authoritative text by two of the leading figures in exercise physiology. Jack Wilmore and Dave Costill have both made an enormous contribution to research in many different areas of exercise science and both are outstanding educators.

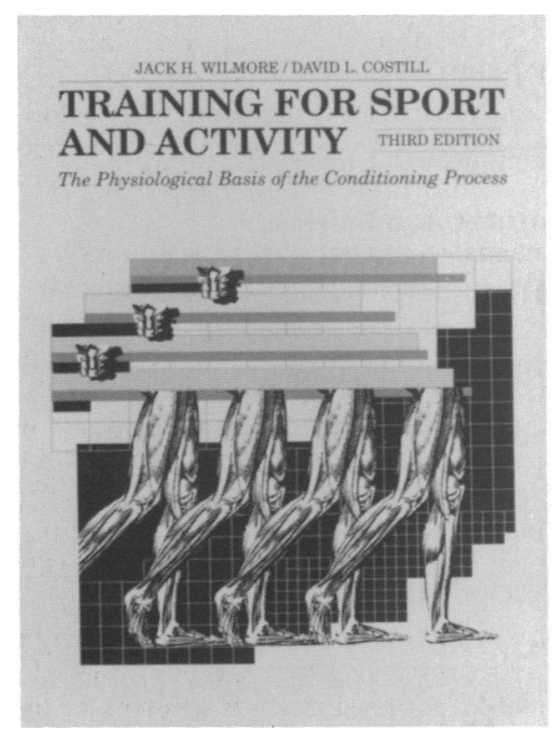

This is a book that students can read (and also one that they can afford to buy, which is unusual now) - the writing style is informative without being pedantic, and whole chapters can be read to get an overview of particular areas. The book is also a comprehensive reference work covering physiology, biochemistry, nutrition and anthropometry in considerable depth. Additional sections reflect the authors' own interests and expertise - as well as the basic science, there are extensive sections on the young athlete, the masters athlete and the female athlete. Further sections on physical activity and health, and on assessment of performance adopt an integrated approach to these topics. The text is profusely illustrated, and if many of the graphs and figures seem familiar, that is probably because others have copied them from the authors' earlier publications. There must be some doubt as to whether all of the photographs make a useful contribution, but at least they do no harm.

There are some minor reservations about the material presented. In some cases, the arguments presented are biased towards the authors' own research data. An example is the information on the metabolic effects of pre-exercise feeding - there are several studies which show that pre-exercise glucose feeding does not result in reactive hypoglycaemia and premature fatigue. These are not presented to balance the one study that does show such an effect. Overall, however, these points are rather insignificant.

This is a book which I will use extensively, and it is one to be recommended.

\section{Ron Maughan PhD}

\section{Neuromuscular Fatigue}

A. J. Sargeant and D. Kernell Amsterdam: Faculty of Human Movement Sciences, ISBN $044485763 \mathrm{X}$, 1993, 212 pp, F 60.00

Thirteen years ago a seminal symposium on muscle fatigue was held in London and published in 1982 as a Ciba Foundation Proceedings, edited by Porter and Whelan. For many of us on the fringes of such work, and for those central to it, the Ciba book was an enormously valued and valuable guide. In 1992 the Royal Netherlands

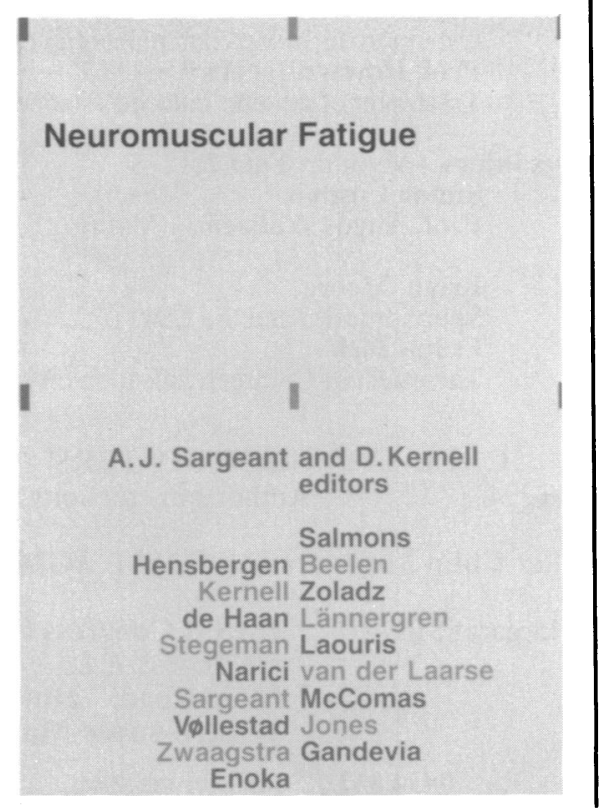

Academy for Arts and Sciences undertook to host a similar symposium and has published the proceedings under the title Neuromuscular Fatigue, edited by Sargeant and Kernell. This is a superb 'state of the art' reference, with its 52 invited contributors reading like a who's who of muscle researchers, although naturally some very well known names are missing.

In 1982, RHT Edwards defined fatigue as 'a failure to maintain the required or expected force' which has been much quoted. This time, Bigland-Ritchie prefers 'any reduction in the force-generating capacity (measured as the MVC), regardless of the task performed', and indeed this makes more sense; e.g. when the task is to generate $25 \% \mathrm{MVC}$, the first definition would claim that no fatigue has occurred even if there has been a loss of $40 \%$ in MVC force. In sport we are also concerned with power decline, which is not necessarily correlated with force. And there is relaxation fatigue.

Throughout the publication, the collective causes of fatigue discussed include: changes in the action potential configuration; failure of T-tubule propagation; decreased calcium release; reduced calcium sensitivity of the contractile proteins; decreased contraction by cross-bridges; decreased phospho-creatine; decreased ATP; increase in inorganic phosphate; lowered $\mathrm{pH}$; rise in inosine monophosphate; increase in magnesium; potassium efflux; carnitine depletion; glycogen depletion; anaplerotic limitation; central fatigue; motoneurone and muscle receptor effects; microdamage; and relaxation fatigue. And the point is made that the function of fatigue is to protect the sensitive links in the system from undesirable and potentially dangerous overuse, which many in sport tend to overlook!

The book is organized into five sections: Cellular Processes of Muscle (eight papers, 32 pp); EMG Related Processes (five papers, $25 \mathrm{pp}$ ); Long Term Processes - useage, ageing and damage - (seven papers, $20 \mathrm{pp}$ ); Muscle Performance - mechanical demand and metabolic supply (12 papers, 58 pp); Neuronal Mechanisms and Processes (eight papers, $50 \mathrm{pp}$ ); and the discussions have been gathered together in a final seven pages.

Quite simply, anyone who valued the 1982 Symposium, and all who have a genuine interest in muscle and fatigue, must have this vital reference on their shelf. For whatever reason, 
most of us oversimplify our explanations of fatigue. If I could paraphrase J.B.S. Haldane, it sometimes seems for too many of us in the sports world that 'Fatigue is not only more complex than we imagine, it is more complex than we can imagine'. This book helps greatly.

Craig Sharp PhD, MRCVS

\section{Exercise Psychology}

Peter Seraganian

Chichester: Wiley-Interscience,

ISBN 047152701 7, 1993, 390 pp.

The field of sport psychology can be divided into two major divisions psychological antecedents of athletic performance and psychological consequences of exercise. The book Exercise Psychology: The Influence of Physical Exercise on Psychological Processes summarizes scientific knowledge about selected aspects of that half of the field concerned with health-related consequences of exercise.

This book has all the strengths and weaknesses of an edited volume. These include, for example, the strength of an experienced researcher writing about a topic that he has been immersed in for many years (e.g. François Péronnet's chapter (with Attila Szabo) concerning sympathetic nervous system responses to acute psychosocial stressors in humans) and the weakness of a lack of consistency in both substance and style across chapters.

The book contains 14 chapters organized into four parts. Part I consists of a single chapter titled 'Historical and conceptual roots of exercise psychology' written by Jack Rejeski and Amy Thompson. Although much of the chapter aptly describes the state of

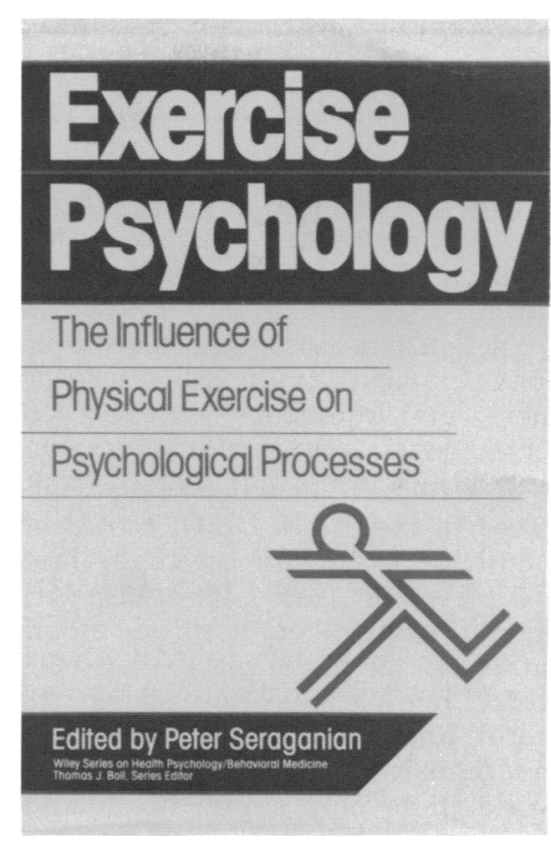

affairs in the field, it also lacks balance by being noncritical about some matters (e.g. results from meta-analyses) and inappropriately critical of other issues.

Part II is titled 'The Status of Relevant Research' and contains chapters by: David Holmes summarizing his research on aerobic. fitness and psychological stress responses (No. 2), Stephen Boutcher describing methods for quantifying aerobic fitness and physical activity (No. 3), Kim Tuson and David Sinyor reviewing the affective consequences of acute aerobic exercise (No. 4), Daniel Landers and colleagues writing about the potential usefulness of meta-analysis in summarizing exercise psychology research (No. 5), Lise Gauvin and Lawrence Brawley proposing alternative methods for the study of exercise and affect (No. 6), François Péronnet and Attila Szabo writing about sympathetic nervous system responses to acute psychosocial stressors (No. 7), and
John Jamieson and Karen Flood who present a chapter that covers basic research methodology issues (No. 8).

Part III is titled 'Applications' and contains chapters by: Roger Fillingim and James Blumenthal about the psychological consequences of exercise in the elderly (No. 9), Lawrence Brawley and Wendy Rodgers about psychosocial aspects of the promotion of activity and fitness at both an individual and community level (No. 10), Thelma Horn and Randal Claytor about the relationship between physical fitness and both self-esteem and reactivity to stressors in children (No. 11), Bonita Long about cognitive aspects associated with emotional responses to exercise (No. 12); and Thomas Plante titled 'Aerobic exercise in the treatment and prevention of psychopathology' (No. 13).

Part IV consists of a single chapter by the editor that overviews the book and addresses selected issues thought to be critical to this area of inquiry. In this chapter it is pointed out that before publication a 2-day conference was held, aimed at promoting coherence across the chapters. Unfortunately, this difficult goal was not achieved.

This book is not comprehensive and in parts there is a lack of accuracy and depth. For example, important topics such as depression, psychoneuroimmunology, eating disorders, and the use and potential of animal models in exercise and mental health research were either ignored or only briefly covered. Despite these shortcomings, this volume has a number of strengths and can be recommended for use in introductory courses, as a single source reference for workers in healthrelated professions who desire information about exercise psychology and as a springboard for further discussion and research dealing with the psychological consequences of exercise.

Patrick J. O'Connor $\mathrm{PhD}$ 